\title{
Attentional requirements on cyclists and drivers in urban intersections
}

Katja Kircher and Christer Ahlström

The self-archived postprint version of this journal article is available at Linköping University Institutional Repository (DiVA):

http://urn.kb.se/resolve?urn=urn:nbn:se:liu:diva-164215

N.B.: When citing this work, cite the original publication.

Kircher, K., Ahlström, C., (2020), Attentional requirements on cyclists and drivers in urban

intersections, Transportation Research Part F, 68, 105-117. https://doi.org/10.1016/j.trf.2019.12.008

Original publication available at:

https://doi.org/10.1016/j.trf.2019.12.008

Copyright: Elsevier

http://www.elsevier.com/

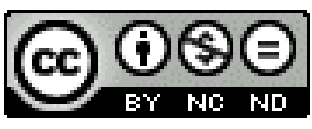




\section{Attentional requirements on cyclists and 2 drivers in urban intersections}

3

Katja Kircher ${ }^{1} \&$ Christer Ahlström ${ }^{1,2}$

$5 \quad{ }^{1}$ Swedish National Road and Transport Research Institute (VTI), Sweden

${ }^{2}$ Department of Biomedical Engineering, Linköping University, Sweden

7

Corresponding author: Katja Kircher; katja.kircher@vti.se

\section{Abstract}

Even though often travelling on the same roads, it has been shown that cyclists and car drivers interpret their environment differently, which can lead to misunderstandings and collisions. Based on the Minimum Required Attention (MiRA) theory and the Salience, Effort, Expectancy, Value (SEEV) model, it is investigated whether the attentional requirements put on drivers and cyclists are different in urban intersections, and how difficult it is to fulfil the requirements for the two road user groups. Additionally, glance data from 23 participants who both cycled and drove along an urban route are compared with respect to information sampling strategies and the fulfilment of attentional requirements depending on its type for three intersections. Generally, more attentional requirements existed for cyclists, and due to where they occur relative to the infrastructure, in combination with the physical aspects of cycling, they are less likely to be fulfilled. This was also corroborated by the empirical data, which showed that requirements clearly visible from the infrastructural design are fulfilled more often than those that are not. Overall, the theoretical evaluation of the infrastructure was confirmed by the empirical data, such that the proposed method can be used as a starting point for a theoretical, human centred evaluation of traffic infrastructure. 


\section{Introduction}

It is a traffic offence to drive "without due care and attention" (Road Traffic Act 1988). In the British law this is described as "allowing the standard of driving to fall below that of a competent and careful driver". For cyclists, "careless, and inconsiderate cycling" is a similar offence, described as "cycling on a road without due care and attention or without reasonable consideration of others" (Road Traffic Act 1988). But what does it mean to be attentive? Are the requirements for being considered attentive the same for drivers and cyclists in the same road environment? Depending on the infrastructure, drivers and cyclists either share the road, or cyclists are encouraged to use different facilities, like a cycle lane or cycle path. This can pose different demands on the two road user groups in terms of when to sample which information from where, and it has been shown previously that different road user groups interpret the same environment differently (Salmon, Lenne, Walker, Stanton, \& Filtness, 2014a, 2014b; Salmon, Young, \& Cornelissen, 2013). Therefore, an investigation of the attentional requirements on the two road user types in various types of infrastructure could provide information about possible factors impeding situation assessment.

In traffic, attention is closely linked to vision (Doshi \& Trivedi, 2012; Sivak, 1996), which is why we focus on visual information sampling in this work. Visual scanning behaviour is governed by attention and depends on the intended action (Clark, 2013, 2016; Itti \& Koch, 2000; Itti, Rees, \& Tsotsos, 2005). Summala, Pasanen, Rasanen, and Sievanen (1996) found that drivers intending to turn right at a Tjunction missed cyclists coming from the right on an adjacent cycle path, as they looked less for traffic coming from the right than for traffic from the left. A follow-up study showed that cyclists more frequently had noticed the car than the driver had noticed the cyclist before an accident, and that in many cases the cyclist expected the driver to yield as required by law. A further study in roundabouts indicated that around $10 \%$ of all drivers did not check for cyclists from the right (Rasanen \& Summala, 2000), and a recent study found that in more than $50 \%$ of uncontrolled intersections, teenage cyclists did not focus into the street coming from the right with right of way.

Driver expectation and attention allocation are recurring factors that are mentioned with respect to traffic conflicts and accidents (Lemonnier, Brémond, \& Baccino, 2015; van Haperen et al., 2018; Werneke \& Vollrath, 2012), but traffic regulations are not the only factor in determining who will yield to whom (Björklund \& Åberg, 2005; van Haperen et al., 2018). If more time is available, there is some evidence that road users tend to scan wider (Lemonnier et al., 2015; Summala, Pasanen, et al., 1996), even though a video-based study with bicyclists did not corroborate this (Kovácsová et al., 2018). However, this might be related to cyclists' speed being relatively low to begin with in comparison to motor vehicles.

Much research exist on attention allocation, mainly operationalised by gaze direction, both for car drivers (e.g. Kircher \& Ahlstrom, 2017a; Lemonnier et al., 2015; Robbins \& Chapman, 2018; Underwood, Chapman, Brocklehurst, Underwood, \& Crundall, 2003; Walker \& Brosnan, 2007; Werneke \& Vollrath, 2012) and cyclists (e.g. Ahlstrom, Kircher, Thorslund, \& Adell, 2015; Frings, Parkin, \& Ridley, 2014; Nygårdhs, Ahlström, Ihlström, \& Kircher, 2018; Stelling-Konczak et al., 2018; Uetake \& Shimoda, 2014). Typically, it is studied what the road user looks at/allocates attention to, depending on various factors. Less frequently it is also investigated what attention should be allocated to in a given situation. This can happen implicitly, for example by adding target road users or safety critical events in a simulator (Donmez, Boyle, \& Lee, 2008; Samuel \& Fisher, 2015), or, like in the studies of Summala, Räsänen and others, by analysing whether drivers of turning vehicles look both to the left and the right (Summala, Pasanen, et al., 1996). 
The objective of this study is to systematically investigate the attentional demands of traffic situations on drivers and bicyclists, and how difficult it is to fulfil these demands. The demand classification is based on the theory of Minimum Required Attention (MiRA; Kircher \& Ahlstrom, 2017b). The MiRA theory suggests that a road user is attentive when all required target areas in a given situation have been attended to. The requirements are connected to the infrastructure and describe which information should be sampled when and from where. The information should be sampled within a so-called zone which is determined by the infrastructure itself, including obstacles and visibility.

The combination of MiRA requirements in a given situation can be evaluated based on the categories in the SEEV model (Wickens, Goh, Helleberg, Horrey, \& Talleur, 2003; Wickens, Helleberg, Goh, Xu, \& Horrey, 2001; Wickens \& Horrey, 2008), assessing the likelihood that all requirements in the situation will be fulfilled. SEEV has mainly been used to model actual attention allocation in pilots but has also been applied to other domains (Cassavaugh, Bos, McDonald, Gunaratne, \& Backs, 2013; Horrey, Wickens, \& Consalus, 2006; Werneke \& Vollrath, 2012). SEEV states that visual behaviour is governed by a combination of the bottom-up factors salience and effort, and the top-down factors expectancy and value. Salient stimuli are more likely to attract attention because of their physical features. A greater effort, for example turning one's body or head to sample from a certain information source, decreases the likelihood to allocate attention to that source. The expectancy of where and when to expect relevant information directs attention allocation and is connected to user experience. Here, expectancy is interpreted such that the infrastructural layout as a whole should guide the road users' expectations correctly. Finally, the value that is expected to be gained from the information source is relevant to attention allocation. In the present context, we see the identification of MiRA requirements as the implementation of value. The MiRA requirements reflect from where information has to be sampled to avoid collisions, which is assumed to be of high value. Therefore, value will not be used for further evaluation of the MiRA requirements.

As pointed out by Horrey et al. (2006), the SEEV model is mainly conceptualised to model foveal scanning, which has to be taken into account for a task like driving, where peripheral vision is actively involved (Lamble, Laakso, \& Summala, 1999; Summala, Lamble, \& Laakso, 1998; Summala, Nieminen, \& Punto, 1996; Wolfe, Dobres, Rosenholtz, \& Reimer, 2017). This is very likely true also for cycling.

Based on the research presented above, we assume that the attentional demands on drivers and cyclists in the same environment differ. We start out with a systematic evaluation of the attentional requirements on drivers and cyclists in three different intersections, followed by an evaluation of the actual visual behaviour of drivers and cyclists in these situations. We use an open-ended approach, as this study is of exploratory character, with the ambition to introduce a possible evaluation framework for evaluating attentional demands in a given infrastructure.

\section{Method}

A web-based questionnaire, distributed via Facebook, asking questions on cycling and driving background, was used to recruit the participants. The questionnaire generated 382 answers from which 23 participants ( $39 \pm 14$ years old, 12 females) were selected. Recruitment criteria were that they had no more than \pm 4 dioptres and did not need any other correction for vision (because of limitations with the eye tracker), that they were willing and able to participate in the study, that they both drove a car and cycled at least sometimes, and that they could bring their own bicycle. Of all respondents, the first ones matching the criteria were contacted. 
114 Upon scheduling the time for the ride and drive, the participant received detailed information about the study. When he or she arrived at the meeting place, an office close to the test route, the information was repeated, and the participant signed an informed consent form. The study was approved by the regional ethical committee in Linköping (Dnr 2017/107-31).

Each participant completed the route twice, once by bicycle and once driving a car. The order was counterbalanced initially, however, practical issues like rescheduling led to 14 participants driving first and nine cycling first. In case of rain, the participant was rescheduled, as the eye tracking equipment was not water resistant. Parts of the route had dedicated cycle infrastructure, parts had combined cyclist and pedestrian lanes and parts had mixed traffic, without cycle infrastructure, but with pedestrian pavements. The route was about $5 \mathrm{~km}$ long and led through both the inner city of Linköping, Sweden, and near-city living areas. Traffic density varied with time of day, with busy periods in the morning and late afternoon and quiet periods during the day. Most participants completed both test runs in succession, therefore encountering comparable conditions for both trips.

\section{Ride}

128 Two GPS-equipped action cams (Garmin Virb, Olathe, Kansas, USA) were mounted on the participant's bicycle, one facing forward, and one directed at the cyclist's face. The participant wore a head-mounted eye tracker (SMI glasses 2.0, SensoMotoric Instruments, Teltow, Germany), which was calibrated indoors using three-point calibration. The route was divided into five segments, and after completing each segment the cyclist received directions to the next stop with the help of a map and verbal instructions. The cyclists were instructed to cycle just as if not participating in a study, at their own pace and choice of positioning. The cyclist was followed by the experimenter at a few metre's distance. The experimenter's bike was equipped with a forward-facing camera. Upon arriving at the end of a segment, the experimenter asked whether anything special had occurred along the way.

Drive

When driving the route, the participant, again wearing the eye tracker, used an instrumented Volvo V60 owned by VTI, which was equipped with a data logger (Video VBOX Pro, RaceLogic, Buckingham, UK) that recorded speed, position, and the view forward, rearward, to the right side and of the driver. The experimenter sat in a rear passenger seat. The procedure was similar as for cycling.

Three intersections along the route were chosen for analyses (Table 1). In all intersections the road user continues straight on, but with differing right-of-way regulations.

Table 1. Description of the three intersections studied.

\begin{tabular}{lll}
\hline type & description & regulation \\
\hline $\begin{array}{l}\text { Stop- } \\
\text { regulated } \\
\text { intersection }\end{array}$ & $\begin{array}{l}\text { mixed traffic on both roads, wide } \\
\text { pedestrian pavement, parked cars } \\
\text { along subordinate road, quiet road, } \\
\text { houses obstructing sight (Table 5 in } \\
\text { the results section) }\end{array}$ & $\begin{array}{l}\text { the participants used the subordinate } \\
\text { road, where all traffic has to yield to all } \\
\text { traffic on the intersecting main road }\end{array}$ \\
$\begin{array}{lll}\text { Unsignalised } \\
\text { intersection }\end{array}$ & $\begin{array}{l}\text { combined cycle- and pedestrian } \\
\text { pavement alongside main road, quiet } \\
\text { road, good view except for some }\end{array}$ & $\begin{array}{l}\text { as drivers, the participants used the main } \\
\text { road, which has priority over the side } \\
\text { roads; as cyclists, the participants used } \\
\text { the combined cycle- and pedestrian }\end{array}$ \\
\hline
\end{tabular}




\begin{tabular}{lll}
\hline & $\begin{array}{l}\text { greenery, wide roads (Table } 6 \text { in the } \\
\text { results section) }\end{array}$ & $\begin{array}{l}\text { pavement next to the road, which } \\
\text { officially does not have priority, even } \\
\text { though the infrastructural design and } \\
\text { common practice suggest that it has }\end{array}$ \\
\hline $\begin{array}{l}\text { Signalised } \\
\text { intersection }\end{array}$ & $\begin{array}{l}\text { dedicated cycle path separated with } \\
\text { a line from pedestrian path, separate } \\
\text { traffic light for cyclists, busy } \\
\text { intersection, cars parallel to cyclist } \\
\text { frequently turn right onto main road, } \\
\text { good view, but many traffic streams } \\
\text { (Table 7 in the results section) }\end{array}$ & $\begin{array}{l}\text { right of way regulated by a traffic light; } \\
\text { dedicated traffic lights for cars, bicyclists } \\
\text { and pedestrians, of which the latter two } \\
\text { can only be green when the former is } \\
\text { green, but the former can be green } \\
\text { without the latter two being green (as } \\
\text { they need to be activated by cyclist or } \\
\text { pedestrian presence) }\end{array}$ \\
\hline
\end{tabular}

The MiRA requirements were determined for each intersection, for cyclists and drivers, based on traffic regulations in combination with visibility preconditions (e. g. houses blocking the line-of-sight) at the site. This was done during an on-site visit before the study was conducted. The requirements were of two types, necessary or useful for own safety. Examples of necessary requirements include looking at traffic lights and left/right in intersections. Useful requirements are generally characterised by a situation where the other road user should give way, but where the frequency of this rule being neglected is relatively high. The extent of the zones within which a target had to be sampled was determined based on the spatial area where the road user had to and could fulfil the requirement.

For each road user, mode of transportation and intersection, a behavioural analysis was made using the Observer XT 14.2 (Noldus Information Technology, Wageningen, The Netherlands). Per MiRAzone, it was determined whether the target was attended to. This happened with several levels of certainty, as described in Table 2. One observer coded all MiRA instances to avoid inter-rater issues. In addition, more detailed glance behaviour was encoded by first classifying the direction for visual information sampling, and then annotating this with a specification of the assumed sampling purpose (Table 3). Again, one observer coded all glance behaviour. Eye tracking quality was qualitatively high for driving but less so for cycling. This is mostly due to car drivers being shielded from direct sunlight by the roof of the car. To minimize exposure to infrared light in the cycling sessions, the study was conducted during autumn when the probability of cloudy weather was high. To further remedy the effect of tracking quality, the glance coding was done manually, so the coder could, to some extent, compensate for static offsets (low accuracy) and "jumpy" eye tracking (low precision). After these measures, eye tracking quality was sufficient for the type of analyses used in this paper.

Table 2. Coding scheme for fulfilment of necessary and useful MiRA requirements

\begin{tabular}{lll}
\hline requirement fulfilled & how & explanation \\
\hline yes & by vision & $\begin{array}{l}\text { eye and head tracking data indicate foveal sampling } \\
\text { from the area }\end{array}$ \\
\hline by behaviour & $\begin{array}{l}\text { no eye tracking data available or no foveal sampling, } \\
\text { but the behaviour indicates knowledge about the } \\
\text { requirement (e. g. stopping at a stop line) }\end{array}$ \\
& $\begin{array}{l}\text { general } \\
\text { impression }\end{array}$ & $\begin{array}{l}\text { no overt behaviour, but inferred from other behaviour } \\
\text { or based on covert signs knowledge about the } \\
\text { requirement can be assumed (e. g. at zebra crossing } \\
\end{array}$ \\
& $\begin{array}{l}\text { with no pedestrians present, but stopped previously for } \\
\text { pedestrians at zebra crossing) }\end{array}$ \\
\end{tabular}




\begin{tabular}{ll}
\hline no & $\begin{array}{l}\text { obviously, no information sampling from the required } \\
\text { direction (only used in cases where a fulfilment would } \\
\text { certainly have required overt behaviour) }\end{array}$ \\
\hline unclear & $\begin{array}{l}\text { no overt or covert indications for sampling, but no clear } \\
\text { signs for non-sampling either }\end{array}$ \\
\hline n/a & $\begin{array}{l}\text { for cyclists, when they chose a path that did not lead } \\
\text { through the MiRA zone, e. g. on the pavement on the } \\
\text { opposite road side }\end{array}$ \\
\hline
\end{tabular}

170

171

172

173

174

175

176

177

178

179

180

181

182

183

184

185

186

187

188

189

190

191

192

Table 3. Coding scheme for detailed glance behaviour analysis.

\begin{tabular}{|c|c|}
\hline sampling direction & $\begin{array}{l}\text { forward } \\
\text { left } \\
\text { right } \\
\text { behind left (left mirror or over shoulder) } \\
\text { behind right (right mirror or over shoulder) } \\
\text { behind centre (mirror centre, only car) } \\
\text { downward (car - cluster etc., bicycle - curb, cycle path, etc.) }\end{array}$ \\
\hline sampling purpose & $\begin{array}{l}\text { default (car - only within forward, bicycle - within forward or downward) } \\
\text { check for potential traffic (e. g. side streets, potentially overtaking traffic) } \\
\text { monitor traffic (e. g. traffic ahead, or other already previously noted traffic) } \\
\text { monitor traffic light, sign, ... (e. g. watch red light for turning green) } \\
\text { other (none of the above) }\end{array}$ \\
\hline
\end{tabular}

Situational complexity was categorised continuously using a method devised in a previous study (Nygårdhs et al., 2018). Based on the video material, one data reductionist coded per participant per role for how long it would have been possible to refrain from taking in visual information, given the current situation, considering both the infrastructure, the current traffic and the travelling speed. Complexity levels ranged from 0 ( $>3 \mathrm{~s}$ ) over 1 (1-3 s) and $2(<1 \mathrm{~s})$ to 3 (not possible to look away) and represent the predictability of the situation. Differences in complexity between riding and driving as a function of distance were analysed using two-sample t-tests using a significance level of 5 $\%$. An additional analyst coded two participants for an inter-rater reliability analysis. The chosen comparison method was based on the duration ratings in agreement versus the duration of ratings not in agreement, regardless of how far apart those ratings were from each other. The two analysts agreed in $83.4 \%$ of the time in the bike condition (Cohen's kappa $=0.69$ ) and in $70 \%$ of the time in the car condition (Cohen's kappa $=0.60$ ). Wilcoxon signed rank tests for related samples were conducted to compare the sampling directions forward, left and right for driving and cycling (alphalevel .05).

\section{Results}

The number of necessary MiRA requirements was equal or higher for cars than cyclists in the same intersection. For cyclists there were useful MiRA requirements in each intersection, whereas there were none for cars (Table 4). Cyclists had a higher maximum number of overlapping zones and a wider required viewing angle than drivers.

Table 4. Number of MiRA-zones and the maximum number of simultaneous zones for bikes and cars per research event.

\begin{tabular}{lllllll}
\hline & stop & & \multicolumn{2}{c}{ un-signalised } & & \multicolumn{2}{c}{ signalised } \\
\hline bike & & car & bike & car & bike & car \\
\hline
\end{tabular}




\begin{tabular}{|c|c|c|c|c|c|c|}
\hline $\begin{array}{l}\text { number of necessary } \\
\text { MiRA zones per } \\
\text { event }\end{array}$ & 3 & 3 & 1 & 2 & 1 & 2 \\
\hline $\begin{array}{l}\text { number of useful } \\
\text { MiRA zones per } \\
\text { event }\end{array}$ & 1 & 0 & 2 & 0 & 2 & 0 \\
\hline $\begin{array}{l}\text { max number of } \\
\text { simultaneous MiRA } \\
\text { zones per event }\end{array}$ & 4 & 3 & 3 & 1 & 3 & 1 \\
\hline $\begin{array}{l}\text { approx. required } \\
\text { viewing angle across } \\
\text { simultaneous zones }\end{array}$ & $180^{\circ}$ & $180^{\circ}$ & $250^{\circ}$ & $60^{\circ}$ & $150^{\circ}$ & $60^{\circ}$ \\
\hline
\end{tabular}

In the following, the MiRA requirements are described for each intersection and theoretically evaluated with the SEEV model. In addition, actual glance behaviour and complexity ratings from the field test are analysed with respect to the requirements.

\section{Stop-regulated intersection}

MiRA requirements: The stop rule implies that it is necessary to sample information from both sides of the intersecting road to make sure that there is a gap of appropriate size. The road users must also make sure that no pedestrian is about to cross the zebra crossings. Cyclists move in mixed traffic, such that their requirements equal those of car drivers. However, due to the cyclists' placement on the right side of the street and the cyclists' smaller size, it is advisable, even though not strictly necessary, to make sure that potential oncoming traffic turning left has noticed the cyclist.

Salience: The zebra crossings and the stop sign are static gaze targets. They are readily visible, and they must be treated in the same way by drivers and cyclists. Other road users are dynamic targets that may potentially appear in the MiRA zones. The salience of those road users depends on their size, colour, movement and appearance and is equal for drivers and cyclists.

Effort: The gaze range for the necessary requirements is equal for drivers and cyclists and is mostly oriented in a forward direction, except at the intersection itself, where the range becomes almost 180 degrees, and if cyclists choose to look over their shoulder as well, even more than that, requiring head movements back and forth. The wider the required gaze range, the further out into the periphery some of the relevant areas will end up.

Expectancy: The necessary requirements are clearly guided by infrastructure-based features, without any implicit necessary rules. Thus, it is clear where relevant information can be expected. Cyclists may be at greater risk to be missed by oncoming traffic turning left, as they are further out of the line of sight and smaller. Therefore, given the value of the information for a cyclist, checking for leftturning oncoming traffic is included as a "useful" requirement. Awareness of this requirement cannot simply be derived from the infrastructure but builds on experience and insight. 


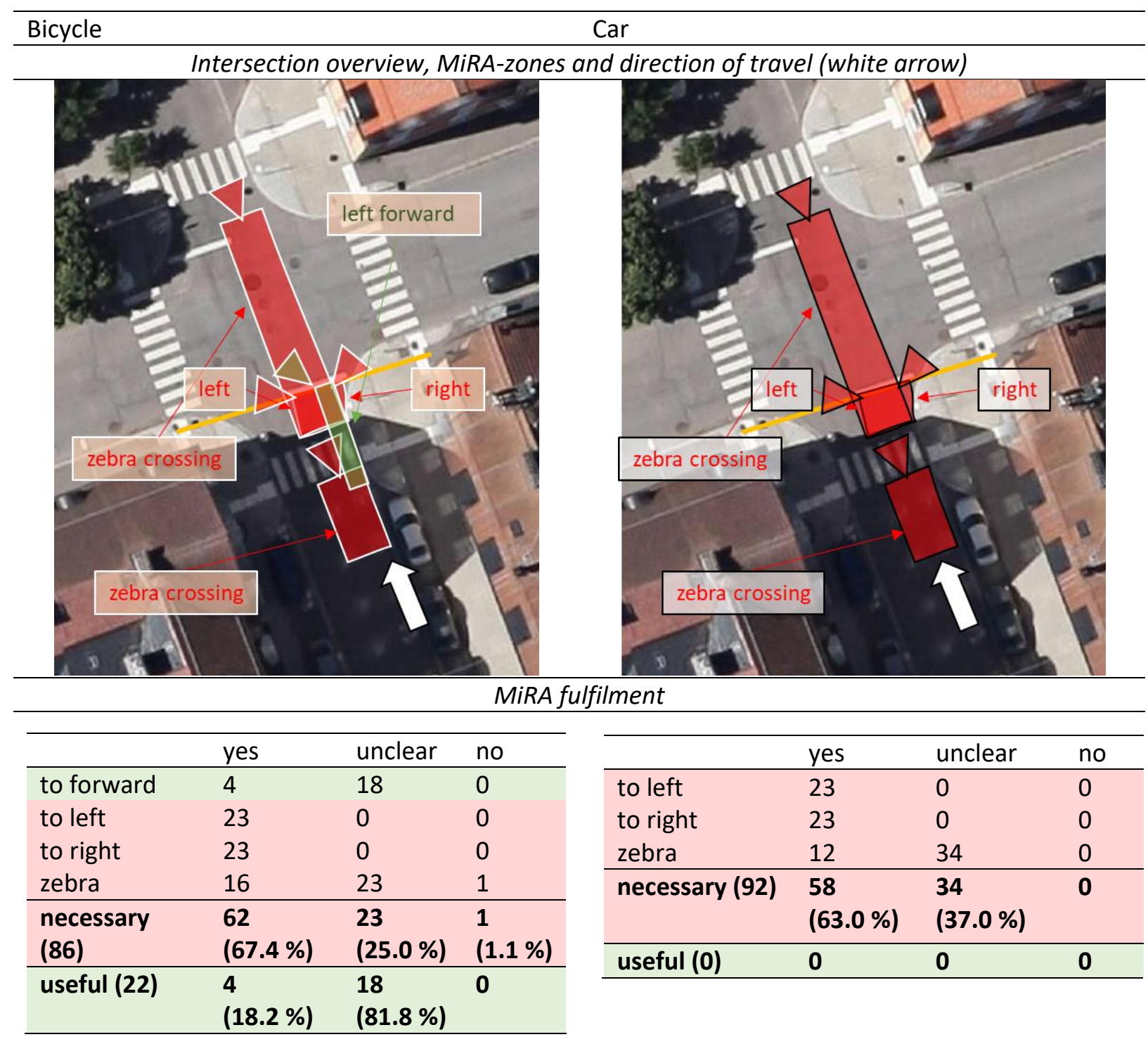

Complexity ratings (mean \pm standard deviation)
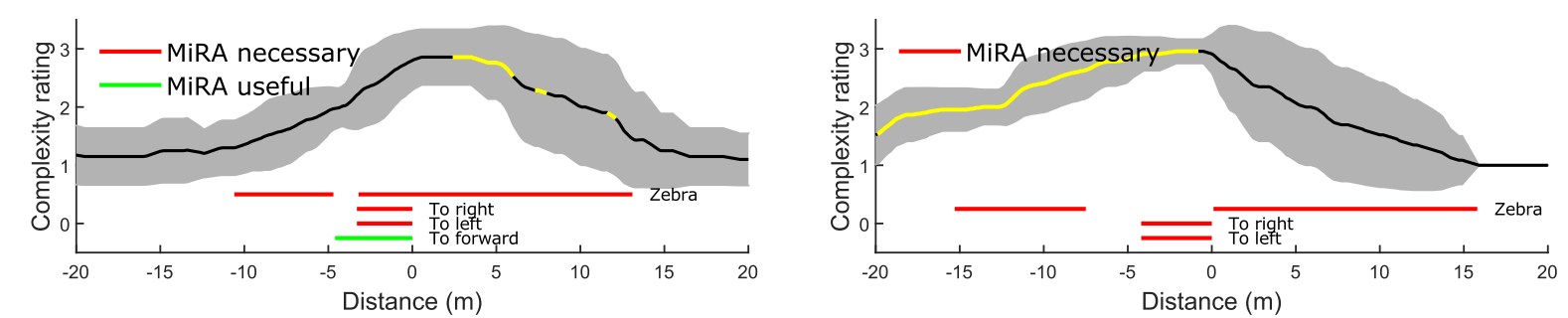

Glance frequency per direction and target type 


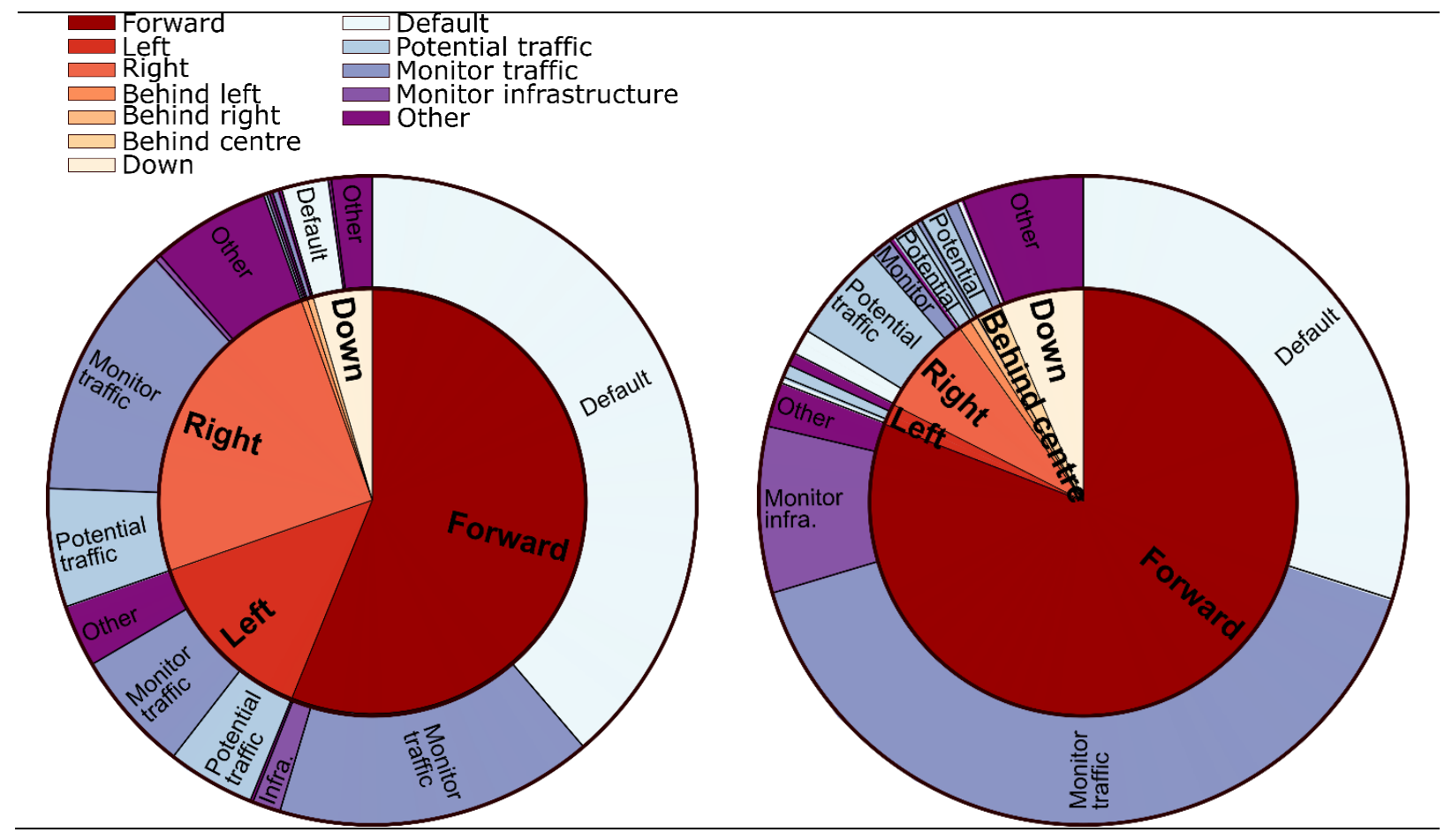

Complexity: For both cyclists and drivers, the complexity level increased towards the middle of the intersection, with higher levels on approach for drivers, but with a steeper incline for cyclists, and with levels remaining high longer for cyclists than drivers.

Behaviour: Cyclists glanced forward less frequently than drivers $(Z=-3.7 ; p<.05)$ and more frequently to the left $(Z=-2.5 ; p<.05)$ and to the right $(Z=-2.5 ; p<.05)$ than drivers did, mostly checking for potential traffic or monitoring traffic. Their share of the "default" category within forward viewing appears to be larger than for drivers, who more frequently monitored traffic and the infrastructure. With respect to the MiRA-zones, both when cycling and driving, all participants checked for traffic from the left and from the right. When no relevant traffic was present, it was often difficult to determine for the coder whether the participant checked for pedestrians at the zebra crossing, or for oncoming traffic potentially turning left.

\section{Unsignalised intersection}

MiRA requirements: This intersection has different attentional requirements for cyclists and drivers. Drivers must make sure that no pedestrian is about to cross the two zebra crossings before and after the intersection. They also have to sample information from the road markings to be able to make an appropriate lane choice on the approach. Cyclists are obliged to consider traffic from the right when entering a bicycle passage. It is also advisable for cyclists to monitor right-turning traffic from behind and left-turning oncoming traffic.

Salience: The driver is on the main road, indicated by a salient traffic sign, but has to yield to potential pedestrians, which is apparent from the salient zebra crossings. Visibility is good and pedestrians should be easy to discern. There are no road signs directly applying to cyclists, but the sign indicating the main road is easily visible to cyclists. The design of the passage across the side road in combination with the sign for main road conveys the (misleading) message that cyclists have right of way. Road users who might cross the cyclists' path can be cars, cyclists and pedestrians. Their salience depends on their size, colour and movement. 
Effort: For motorised vehicles, the MiRA zones are in the forward direction, do not overlap, and are long enough to be assessed conveniently. For cyclists, the MiRA zones overlap and require a head movement to the right for the necessary zone, as well as head movements to left forward and over the left shoulder for the useful zones. The line of sight to potential road users coming from the right is partially blocked by shrubbery, leading to an increased effort in checking for traffic from this 257 direction.

Expectancy: For drivers going straight, the traffic regulations are explicitly visible from static cues like traffic signs and road markings, indicating from where to expect relevant information. The right-ofway rule for cyclists is not obvious, as in Sweden, the cycle path is not necessarily considered part of the main road. Consultation with a legal practitioner led to the attentional requirement for cyclists to check for traffic from the right before venturing into the lane being set as "necessary". This creates a contrast with the existing salient road markings and signs, thereby misguiding expectations. The "main road" sign in the cyclists' direction, in combination with the yield sign and road markings on the road coming from the right suggest that the cyclist has right of way, which may make cyclists expect free passage. Furthermore, the information of whether a car going parallel with the cyclist is about to turn right, or whether an oncoming car is about to turn left, is of high value to the cyclist as they would cross his or her path. Even though cars should yield to cyclists in that situation, this information is not explicit in the environment for either cars or cyclists, which means that they have to rely on learnt rules and experience or insight.

Table 6. MiRA zones and MiRA zone fulfilment for cyclists and drivers, complexity distribution and glance frequency to various areas and glance purpose. Red zones are "necessary", green zones are "useful". The triangles indicate from which direction information should be sampled and the text indicates where the information has to be sampled from. The yellow line is the reference for the zero-distance point in the complexity figures below. Yellow segments in the complexity curve illustrate where the complexity is significantly higher compared to the other transportation mode. Numbers do not always add up to multiples of 23, as there are cases where cyclists chose different lines through the intersection. Map source: (C) Lantmäteriet/Metria

\begin{tabular}{l} 
Unsignalised intersection \\
$\begin{array}{l}\text { Bicycle Car } \\
\text { Intersection overview, MiRA-zones and direction of travel (white arrow) }\end{array}$ \\
\hline
\end{tabular}



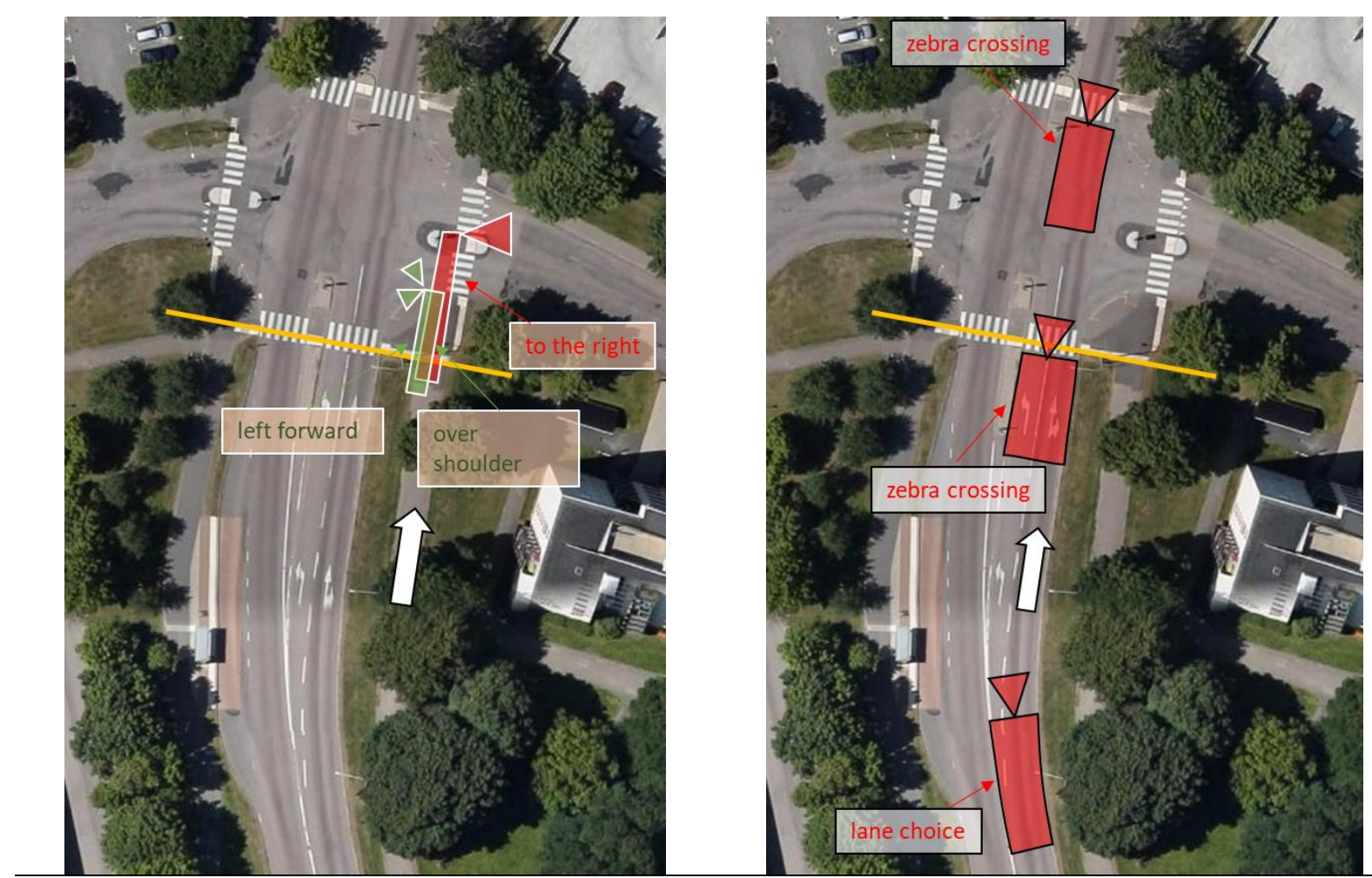

MiRA fulfilment

\begin{tabular}{|c|c|c|c|c|c|c|c|}
\hline & yes & unclear & no & & yes & unclear & no \\
\hline to forward & 1 & 22 & 0 & zebra & 14 & 32 & 0 \\
\hline $\begin{array}{l}\text { over } \\
\text { shoulder }\end{array}$ & 6 & 0 & 17 & $\begin{array}{l}\text { lane } \\
\text { choice }\end{array}$ & 23 & 0 & 0 \\
\hline to right & 18 & 0 & 5 & necessary & & & 0 \\
\hline $\begin{array}{l}\text { necessary } \\
\text { (23) }\end{array}$ & $\begin{array}{l}18 \\
(78.3 \%)\end{array}$ & 0 & $\begin{array}{l}5 \\
(217 \%)\end{array}$ & (69) & (53.6\%) & (46.4\%) & \\
\hline useful (46) & $\begin{array}{l}7 \\
(15.2 \%)\end{array}$ & $\begin{array}{l}22 \\
(47.8 \%)\end{array}$ & $\begin{array}{l}17 \\
(37.0 \%)\end{array}$ & useful (0) & 0 & 0 & 0 \\
\hline
\end{tabular}

Complexity ratings (mean \pm standard deviation)
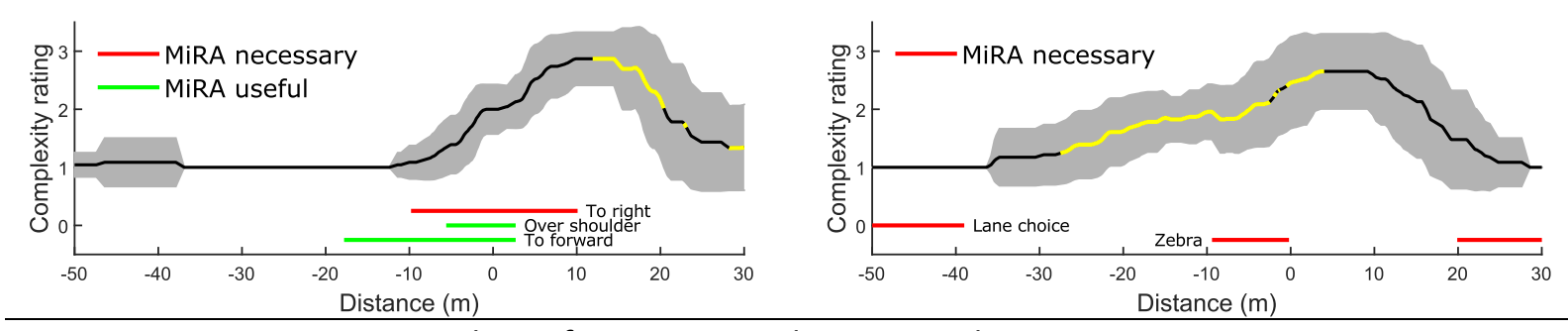

Glance frequency per direction and target type 


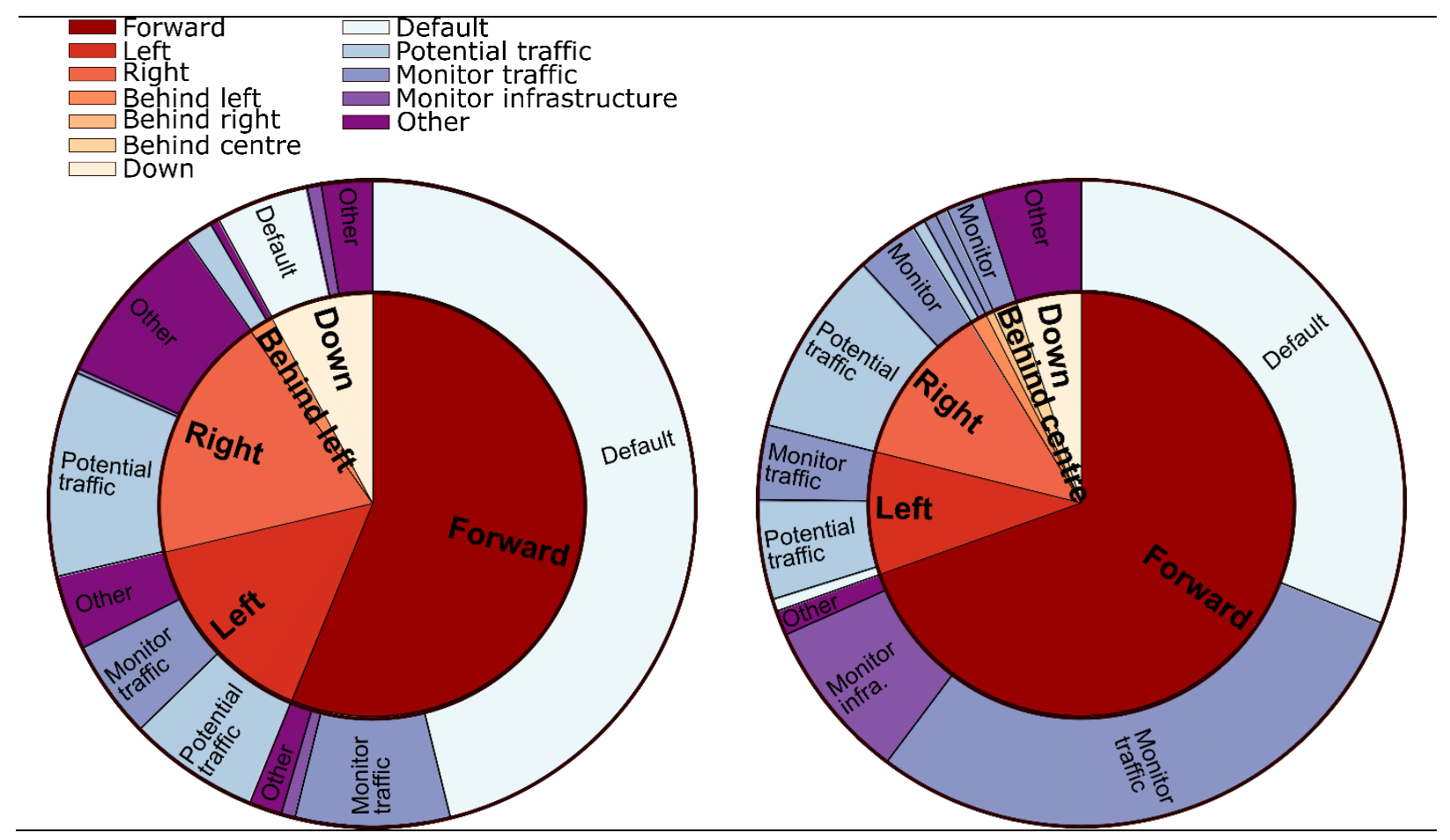

Complexity: For both drivers and cyclists, complexity increased upon approaching the intersection, with higher levels earlier on for drivers, but a steeper incline for cyclists, for whom complexity also reaches a higher level, decreasing first later in the intersection.

Behaviour: Car drivers spent more time with their gaze directed at the forward roadway than cyclists $(Z=-3.2 ; p<.05)$, while cyclists were more prone to collect information from the right $(Z=-2.8 ; p<$ $.05)$, possibly reflecting the formally different right-of-way situations between drivers and cyclists. There was no statistical difference in the glance frequency to the left $(Z=-2.8 ; p<.05)$. Like in the stop-regulated intersection, the "default" category appears larger for cyclists than for drivers when viewing the forward scene, while drivers appear to have monitored the infrastructure more frequently than cyclists did. As for the MiRA requirements, five of the participants did not visually check for potential traffic coming from the right while cycling, while all others did. About half of the participants turned their head to check over the shoulder for potentially right-turning traffic. It was unclear whether cyclists checked for oncoming traffic potentially turning left, when no such traffic was present.

\section{Signalised intersection}

Drivers and cyclists have separate traffic lights in this intersection, and the state of these traffic lights may differ. Cyclists only get green when they either activate an induction loop in the ground upon approach to the intersection or press a button directly at the intersection.

MiRA requirements: It is necessary for both cyclists and drivers to check the current state of the relevant traffic light. Car drivers also have to sample information from the road markings to be able to make a lane choice while approaching the intersection. Even with green light and right of way, it is advisable for cyclists to check for potentially right-turning traffic from behind and left-turning oncoming traffic.

Salience: The traffic lights for motorised traffic are more salient, as they are bigger, more centrally located, and more in quantity. Cyclists have less salient lights that can show red the same time as the traffic lights for motorised traffic show green. Also, cyclists need to notice that they may have to 
press the push button at hip height to activate the green light. Drivers must identify which lane to choose, based on road markings which are visible in the forward view as long as no other cars hide them. Visibility is good, and as above, the salience of other road users depends on their size, colour and movement.

Effort: The drivers' required sampling direction is mainly from forward, up to an angle of around 60 degrees when monitoring the traffic light from the first position at the stop line. Drivers must choose which lane to use and to make sure the traffic light is green when they go. Their MiRA zones are not overlapping and are rather large. This is keeping the required effort down. Cyclists are required to watch the traffic light, and it is useful for them to check for oncoming cars turning left and for parallel traffic turning right. This requires head movements, covering a visual angle of around 160 degrees. The necessary and useful MiRA zones for cycling overlap.

Expectancy: For drivers and cyclists going straight on, all regulations are explicitly visible via the traffic lights. For cyclists it is "useful" to keep an eye on oncoming traffic turning left, which is not based on rules and not explicit, requiring experience and insight. The risk that traffic turning left will miss a car going straight is smaller than missing a bike going straight, as the bike is smaller, further away from the central field of view for the oncoming driver, and positioned at the edge of the intersection, where focus already is on the following road section. Also, for cyclists it is useful to make sure that no parallel car is turning right, crossing the cyclist's path, again, requiring experience or insight to guide expectations.

Table 7. MiRA zones and MiRA zone fulfilment for cyclists and drivers, complexity distribution and glance frequency to various areas and glance purpose. Red zones are "necessary", green zones are "useful". The triangles indicate from which direction information should be sampled and the text indicates where the information has to be sampled from. The yellow line is the reference for the zero-distance point in the complexity figures below. Yellow segments in the complexity curve illustrate where the complexity is significantly higher compared to the other transportation mode. Numbers do not always add up to multiples of 23, as there are cases where cyclists chose different lines through the intersection. Map source: CLantmäteriet/Metria

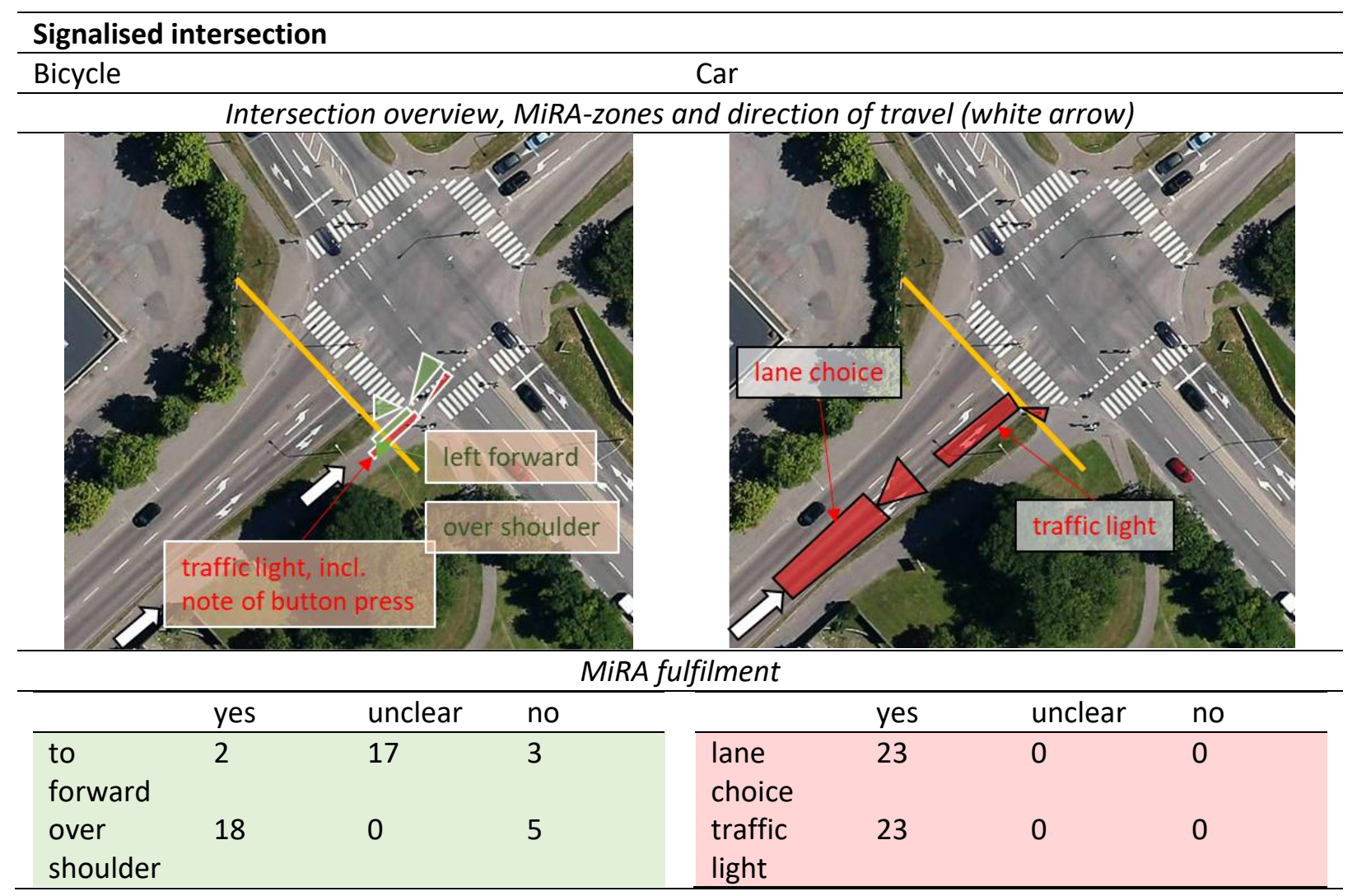




\begin{tabular}{|c|c|c|c|c|c|c|c|}
\hline $\begin{array}{l}\text { traffic } \\
\text { light }\end{array}$ & 23 & 0 & 0 & $\begin{array}{l}\text { necessary } \\
\text { (46) }\end{array}$ & $\begin{array}{l}46 \\
(100 \%)\end{array}$ & 0 & 0 \\
\hline $\begin{array}{l}\text { necessary } \\
\text { (23) }\end{array}$ & $\begin{array}{l}23 \\
(100 \%) \\
\end{array}$ & 0 & 0 & useful (0) & 0 & 0 & 0 \\
\hline $\begin{array}{l}\text { useful } \\
\text { (45) }\end{array}$ & $\begin{array}{l}20 \\
(44.4 \%) \\
\end{array}$ & $\begin{array}{l}17 \\
(37.8 \%) \\
\end{array}$ & $\begin{array}{l}8 \\
(17.8 \%) \\
\end{array}$ & & & & \\
\hline
\end{tabular}
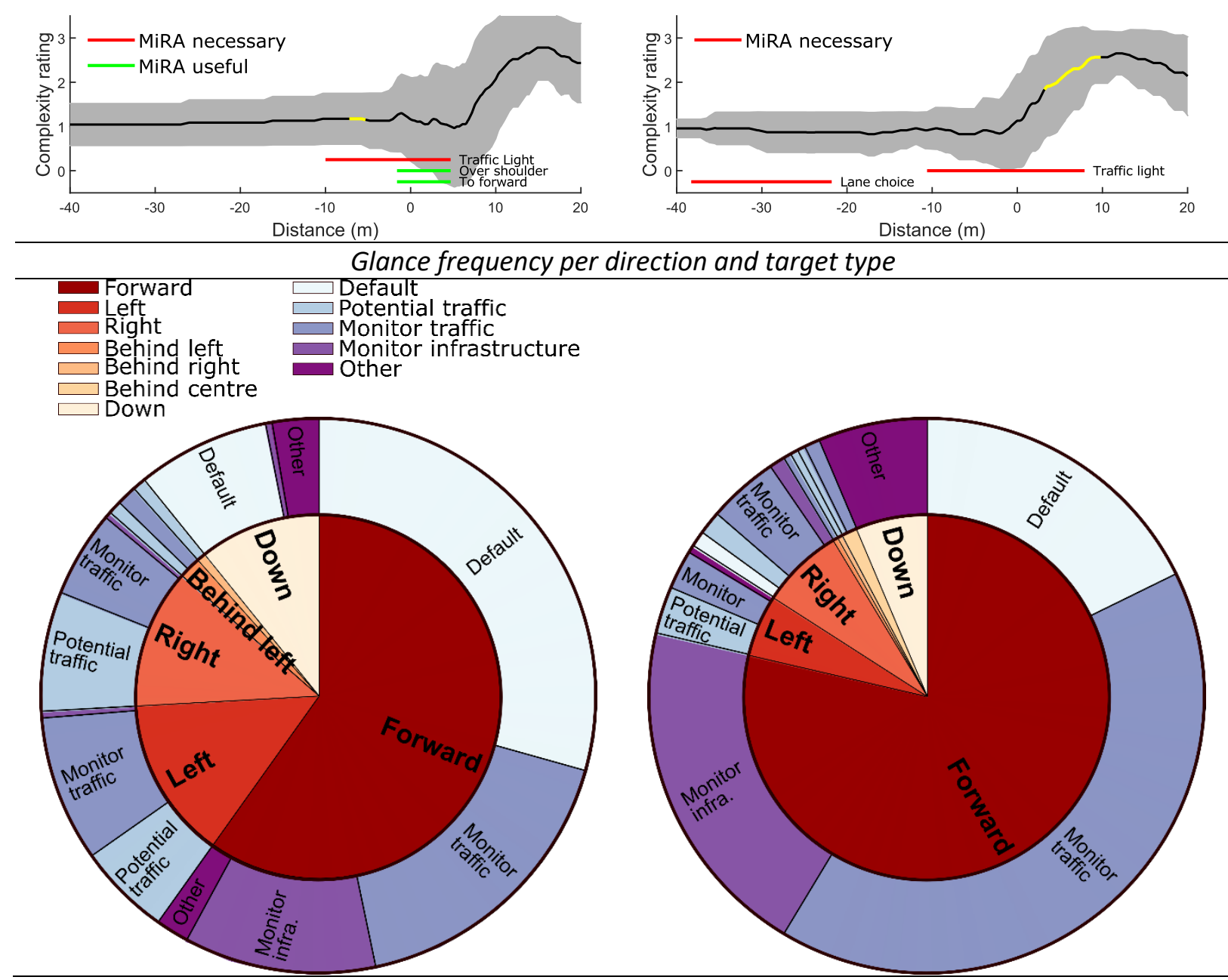

Complexity: For both road user types, complexity increased with the start of the intersection, with the increase starting somewhat earlier for drivers. Overall, the complexity curves were quite similar for both groups.

Behaviour: Again, the share of forward viewing was less for cyclists than car drivers $(Z=-2.9 ; p<.05)$, and the "default" category within forward appears larger for cyclists. Also, drivers appear to have been more likely to monitor the infrastructure, which, in this case, mainly means monitoring the traffic light. Cyclists more frequently checked for potential traffic or monitored traffic on the left $(Z=$ $-3.8 ; p<.05)$, and on the right $(Z=-3.7 ; p<.05)$. All participants monitored the traffic light for green light, and as car drivers, they chose the correct lane. As cyclists, in five of the cases the participants did not glance over their shoulder for potentially turning traffic, and in three of the cases they clearly did not check for potentially left-turning oncoming traffic. In 17 cases, this could not clearly be determined from the data. 
In the three investigated intersections, the salience of necessary sampling targets is either similar for both road user groups or higher for drivers. The information sampling effort is generally higher for cyclists, as wider head movements are required and the timing of the information sampling is more demanding, with more overlapping MiRA zones for cyclists than for drivers. Expectations are guided more explicitly for drivers than for cyclists, especially when it comes to situations where the road user has to rely on experience to determine the likelihood that another road user will follow the rules. This experience then governs the fulfilment of "useful" MiRA requirements. Especially in the case of the unsignalised intersection, the conflict between the salient message to cyclists that the cycle path would be part of the main road, while it in fact is not, shows the importance of congruency between salient information and rules to guide expectations correctly.

The share of non-forward glances was higher for cyclists than drivers regardless of intersection type. Overall, cyclists had a higher frequency of the "default" glance purpose category. As cyclists, the participants glanced at "other" things more frequently than as drivers.

Despite the lower travel speed, the complexity while cycling was about as high as for drivers, with a tendency to increase later but faster on average. Also, increased complexity for cyclists was often associated with the presence of MiRA zones, while there could be MiRA zones for car drivers that were not associated with an increase in complexity. Those were typically on the link before the intersection, with sampling regions extending forward.

For car driving, no necessary MiRA-requirements were clearly missed. As cyclists, the same participants missed necessary requirements in six cases and useful requirements in 25 cases. Generally, fulfilment was "unclear" when peripheral vision sufficed to determine the presence of relevant road users, such that in their absence no foveation and no behavioural changes were necessary.

\section{Discussion}

The MiRA theory in combination with a SEEV-model-based evaluation proved to be a useful method to assess traffic infrastructure for the attentional demands it puts on different road user groups, and the associated difficulty of fulfilling these demands. The SEEV-framework provides a formal structure for the evaluation of the MiRA-zones present in a traffic situation. While every single MiRA-zone might be connected to salient features in the environment, an overlap of several zones within a short distance, especially with varying sampling directions, would still imply a high effort. Salient features that misdirect expectancies are potentially dangerous both in the situation at hand, but also in how they contribute to building up expectancies in similar situations.

The empirical data showed that the differences identified with MiRA and SEEV also lead to different information sampling between the road user groups. Even though the same participants performed the same manoeuvre in the same intersections as both cyclists and car drivers, the infrastructural and situational demands on their information sampling differed markedly depending on transport mode. At the same time as cyclists are physically more vulnerable, they are also confronted with an environment that communicates expectations less clearly. Because of their timing, these expectations are also more difficult to fulfil. This will be elaborated in more detail below. the differences in positioning of the cyclist and the car in the same environment are a large contributing factor to the attentional requirements put on the road user. A separated infrastructure 
leads to differences in attentional demands where the paths intersect, but even in mixed traffic, the positioning of the cyclist at the edge of the lane leads to different attentional requirements.

A higher number of "useful" requirements implies that the knowledge about them is less evident in the infrastructure. The fulfilment of useful requirements contributes to increased situation awareness (Endsley, 1995), and it is likely that they have to be learnt over time and are road user type specific, whereas information about necessary requirements often is more readily available in the infrastructure in the form of signs, lines or construction. The empirical data support this, showing that useful requirements were missed more frequently than necessary requirements. In addition, the necessary requirement missed most frequently contains an ambivalent situation, where the construction and signage of the infrastructure as well as informally applied rules imply right of way for the cyclist, but the actual regulation gives right of way to traffic from the right (Trafikförordning 1998:1276).

399

400

401

402

403

404

405

406

407

408

409

410

411

412

413

414

The analyses here compared the same manoeuvre - going straight on - for intersections with different right-of-way regulations. The combined MiRA and SEEV analyses show that for this manoeuvre type the requirements on the car driver are explicit and readily visible from the environment. A left or right turn would change this picture, as drivers would have to monitor for traffic going straight, without being prompted by the environment. It is expected that this situation leads to more missed requirements for car drivers.

For cyclists, the number of overlapping MiRA zones is higher than for drivers, and the angle from which information has to be sampled in overlapping zones is larger. In separated traffic, the cyclists' zones are often shorter than the cars' zones. Zone extent, the number of simultaneous zones and the required angle from which information must be sampled all influence the ease of requirement fulfilment and the associated effort. Lower speeds increase the available time for information sampling, and typically cyclists have lower speeds than cars. Speed reductions, on the other hand, demand more effort from the cyclist, as this entails a subsequent acceleration to the desired speed. Cyclists generally look left and right more frequently than drivers, which can be a consequence of the wider required sampling angles. Also, bicycles typically do not have mirrors, which necessitates over the shoulder glances for visual monitoring of traffic from behind. However, cyclists also have a larger amount of "default" glances. This indicates that for cyclists, as compared to drivers, the demand distribution is more extreme - either low or high. This is also corroborated by the complexity distributions, which have steeper inclines for cyclists and more often lie at either high or low levels.

These results complement and match the findings by Salmon et al. (Salmon et al., 2014a, 2014b; Salmon et al., 2013), which, based on verbal protocol analysis, showed that different road user groups interpret the same environment differently. Here, it is shown that also the attentional demands and the difficulty of fulfilling the demands differ between road user groups in the same environment, which leads to different sampling behaviours and can very well be a contributing factor to the different interpretations. Therefore, it can be discussed whether the same geographical space really constitutes an equal situation, or whether one infrastructural design caters differently to different road user groups, thereby creating inequality in the same place. Based on the current data, it can be excluded that the differences in performance depend on self-selection of people into different transport modes, because of the within-subjects design where all participants used both transport modes.

In the present study, the empirical assessment of MiRA requirement fulfilment was based on eye and head tracking as well as behaviour observation. Where no head movement, foveating or behavioural adaptation, like stopping or choosing the right lane, were available, but the information sampling 
direction was well within the peripheral field of view, it was not possible to determine whether the requirement was fulfilled or not. A typical example is a zebra crossing ahead. When approaching the zebra crossings with a good view from afar, as was the case here, peripheral vision is sufficient to determine whether pedestrians are present or not. If there are, this typically generates a fixation in their direction, confirming that the requirement was fulfilled. With no pedestrians present, this fixation does not take place, even though the requirement may well be fulfilled. Here, a method like the verbal protocol (Ericsson \& Simon, 1980) could help reduce the uncertainty in data reduction and provide further insights into how the sampled information is integrated. Additionally, this would help gain insight into whether and how information is sampled via non-visual modalities. The exact delimitations of the MiRA zones can also be discussed as they should be connected to speed, brake capacity and, for example, the status of a traffic light. "Useful" zones have a higher subjective component than necessary zones, but can give an indication for the explicitness of rules and the associated SEEV-"value" per road user group.

There are some limitations to this study. First, the presence of an experimenter, both in the car and as following cyclist, as well as the logging equipment, can have influenced the participants' behaviour. Our attempts to minimise the effect included the presence of an experimenter and comparable logging equipment for both transport modes as well as the clear assertion that we were interested in typical behaviour. If there were experimenter effects, we assume them to be similar for both conditions, which should still enable a meaningful comparison. Second, the data reduction, both with respect to glance target assessment and complexity ratings, are at risk to include a subjective component. Ideally, several raters should have performed all assessments to establish robust inter-rater reliability, but the available resources did not allow this. Therefore, we chose to let one person perform all ratings of the same kind, to ensure that there would be no rater-based differences between participants, and performed only a minor inter-rater analysis, which delivered satisfactory results. An more rigorous inter-rater validation would be desirable as future development. Third, the analysis was limited to one manoeuvre in three intersections. Different manoeuvres and additional infrastructural designs, combined with the suggested method improvements, would add to generalisability and identification of successful and problematic designs.

\section{Conclusions}

The existing infrastructure is geared towards motorised vehicles (Knoflacher, 2009), marginalising bicyclists (Koglin \& Rye, 2014). The present data show that this also has consequences for the attentional demands made on the different road user groups. Further, the data indicate that requirements that are made explicit via infrastructural features are fulfilled more frequently than implicit requirements. To promote safety and enhance situational awareness across road user groups, it is therefore recommended to build infrastructure with explicit requirements for all manoeuvres that can be performed. For the specific promotion of cycling as an at least equitable mode of transportation, it is recommended to analyse existing and new infrastructure for the adequacy of demands put on all road user groups from a user-centric perspective. The MiRA/SEEV approach used here is recommended as a starting point, even though it is acknowledged that improvements in the approach can be made.

\section{Acknowledgements}

We would like to thank Harry Sörensen, VTI, for the equipment of the research vehicle and team of experimenters for all help with the data collection. 
Funding: This work was supported by the Swedish Strategic Vehicle Research and Innovation Programme (FFl; grant number 2017-05526).

\section{References}

Ahlstrom, C., Kircher, K., Thorslund, B., \& Adell, E. (2015). Bicyclists' visual strategies when conducting self-paced vs. system-paced smartphone tasks in traffic. Transportation Research Part F: Traffic Psychology and Behaviour, 41(B), 204-216. doi:http://dx.doi.org/10.1016/i.trf.2015.01.010

Björklund, G. M., \& Åberg, L. (2005). Driver behaviour in intersections: Formal and informal traffic rules. Transportation Research Part F: Traffic Psychology and Behaviour, 8(3), 239-253. doi:https://doi.org/10.1016/i.trf.2005.04.006

Cassavaugh, N., Bos, A., McDonald, C., Gunaratne, P., \& Backs, R. W. (2013). Assessment of the SEEV model to predict attention allocation at intersections during simulated driving. Paper presented at the Seventh International Driving Symposium on Human Factors in Driver Assessment, Training and Vehicle Design, Bolton Landing, New York.

Clark, A. (2013). Whatever next? Predictive brains, situated agents, and the future of cognitive science. Behavioral and Brain Sciences, 36(3), 181-204. doi:10.1017/S0140525X12000477

Clark, A. (2016). Attention alters predictive processing. Behavioral and Brain Sciences, 39. doi:10.1017/S0140525X15002472

Donmez, B., Boyle, L. N., \& Lee, J. D. (2008). Mitigating driver distraction with retrospective and concurrent feedback. Accident Analysis \& Prevention, 40(2), 776-786. doi:http://dx.doi.org/10.1016/i.aap.2007.09.023

Doshi, A., \& Trivedi, M. M. (2012). Head and eye gaze dynamics during visual attention shifts in complex environments Anup Doshi Related research. Journal of Vision, 12, 1-16. doi:10.1167/12.2.9.Introduction

Endsley, M. R. (1995). Toward a theory of situation awareness in dynamic systems. Human Factors, 37(1), 32-64.

Ericsson, K. A., \& Simon, H. A. (1980). Verbal reports as data. Psychological Bulletin, 87(3), 215-251. doi:10.1037/0033-295X.87.3.215

Frings, D., Parkin, J., \& Ridley, A. M. (2014). The effects of cycle lanes, vehicle to kerb distance and vehicle type on cyclists' attention allocation during junction negotiation. Accident Analysis \& Prevention, 72, 411-421. doi:https://doi.org/10.1016/j.aap.2014.07.034

Horrey, W. J., Wickens, C. D., \& Consalus, K. P. (2006). Modeling drivers' visual attention allocation while interacting with in-vehicle technologies. Journal of Experimental Psychology: Applied, 12(2), 67-78. doi:10.1037/1076-898x.12.2.67

Itti, L., \& Koch, C. (2000). A saliency-based search mechanism for overt and covert shifts of visual attention. Vision Research, 40(10-12), 1489-1506. doi:http://dx.doi.org/10.1016/S0042-6989(99)00163-7

Itti, L., Rees, G., \& Tsotsos, J. K. (2005). Neurobiology of attention. Us: Elsevier Science/JAI Press.

Kircher, K., \& Ahlstrom, C. (2017a). Evaluation of methods for the assessment of attention while driving. Accident Analysis \& Prevention. doi: http://dx.doi.org/10.1016/i.aap.2017.03.013 
Kircher, K., \& Ahlstrom, C. (2017b). Minimum Required Attention: A human-centered approach to driver inattention. Human Factors: The Journal of the Human Factors and Ergonomics Society, 59(3), 471-484. doi:10.1177/0018720816672756

Knoflacher, H. (2009). From myth to science in urban and transport planning: From uncontrolled to controlled and responsible urban development in transport planning. International Journal of Injury Control and Safety Promotion, 16(1), 3-7. doi:10.1080/17457300902723275

Koglin, T., \& Rye, T. (2014). The marginalisation of bicycling in Modernist urban transport planning. Journal of Transport \& Health, 1(4), 214-222. doi:https://doi.org/10.1016/j.jth.2014.09.006

Kovácsová, N., Cabrall, C. D. D., Antonisse, S. J., de Haan, T., van Namen, R., Nooren, J. L., . . . de Winter, J. C. F. (2018). Cyclists' eye movements and crossing judgments at uncontrolled intersections: An eye-tracking study using animated video clips. Accident Analysis and Prevention, 120, 270-280. doi:10.1016/j.aap.2018.08.024

Lamble, D., Laakso, M., \& Summala, H. (1999). Detection thresholds in car following situations and peripheral vision: implications for positioning of visually demanding incar displays. Ergonomics, 42(6), 807-815.

Lemonnier, S., Brémond, R., \& Baccino, T. (2015). Gaze behavior when approaching an intersection: Dwell time distribution and comparison with a quantitative prediction. Transportation Research Part F: Traffic Psychology and Behaviour, 35, 60-74. doi:10.1016/j.trf.2015.10.015

Nygårdhs, S., Ahlström, C., Ihlström, J., \& Kircher, K. (2018). Bicyclists' adaptation strategies when interacting with text messages in urban environments. Cognition, Technology \& Work, 20(3), 377-388. doi:10.1007/s10111-018-0478-y

Rasanen, M., \& Summala, H. (2000). Car Drivers' Adjustments to Cyclists at Roundabouts. Transportation Human Factors, 2(1), 1-17. doi:10.1207/STHF0201_1

Road Traffic Act 1988. c52, Part 1, Section 3. Retrieved from https://www.legislation.gov.uk/ukpga/1988/52/section/3

Road Traffic Act 1988. c52, Part 1, Section 29. Retrieved from http://www.legislation.gov.uk/ukpga/1988/52/section/29\#commentary-c1397220

Robbins, C. J., \& Chapman, P. (2018). Drivers' visual search behavior toward vulnerable road users at junctions as a function of cycling experience. Human Factors, 60(7), 889-901. doi:10.1177/0018720818778960

Salmon, P. M., Lenne, M. G., Walker, G. H., Stanton, N. A., \& Filtness, A. (2014a). Exploring schema-driven differences in situation awareness between road users: an on-road study of driver, cyclist and motorcyclist situation awareness. Ergonomics, 57(2), 191209. doi:10.1080/00140139.2013.867077

Salmon, P. M., Lenne, M. G., Walker, G. H., Stanton, N. A., \& Filtness, A. (2014b). Using the Event Analysis of Systemic Teamwork (EAST) to explore conflicts between different road user groups when making right hand turns at urban intersections. Ergonomics, 57(11), 1628-1642. doi:10.1080/00140139.2014.945491

Salmon, P. M., Young, K. L., \& Cornelissen, M. (2013). Compatible cognition amongst road users: The compatibility of driver, motorcyclist, and cyclist situation awareness. Safety Science, 56, 6-17. doi:http://dx.doi.org/10.1016/i.ssci.2012.02.008

Samuel, S., \& Fisher, D. L. (2015). Evaluation of the minimum forward roadway glance duration critical to latent hazard detection. Paper presented at the Transportation 
Research Board 94th Annual Meeting, Washington DC, USA. http://trid.trb.org/view.aspx?id=1337244

Sivak, M. (1996). The information that drivers use: Is it indeed $90 \%$ visual? Perception, 25, 1081-1089.

Stelling-Konczak, A., Vlakveld, W. P., van Gent, P., Commandeur, J. J. F., van Wee, B., \& Hagenzieker, M. (2018). A study in real traffic examining glance behaviour of teenage cyclists when listening to music: Results and ethical considerations. Transportation Research Part F: Traffic Psychology and Behaviour, 55, 47-57. doi:https://doi.org/10.1016/j.trf.2018.02.031

Summala, H., Lamble, D., \& Laakso, M. (1998). Driving experience and perception of the lead car's braking when looking at in-car targets. Accident Analysis \& Prevention, 30(4), 401-407. doi:https://doi.org/10.1016/S0001-4575(98)00005-0

Summala, H., Nieminen, T., \& Punto, M. (1996). Maintaining lane position with peripheral vision during in-vehicle tasks. Human Factors, 38(3), 442-451.

Summala, H., Pasanen, E., Rasanen, M., \& Sievanen, J. (1996). Bicycle accidents and drivers' visual search at left and right turns. Accident Analysis and Prevention, 28(2), 147-153.

Trafikförordning (1998:1276), 6 kap., $6 \S$ Trafik med cykel och moped vid färd på väg.

Uetake, T., \& Shimoda, M. (2014). Detecting the gazing attention points of young and elderly cyclists. Journal of human ergology, 43(1), 41-49.

Underwood, G., Chapman, P., Brocklehurst, N., Underwood, J., \& Crundall, D. (2003). Visual attention while driving: sequences of eye fixations made by experienced and novice drivers. Ergonomics, 46, 629-646. doi:10.1080/0014013031000090116

van Haperen, W., Daniels, S., De Ceunynck, T., Saunier, N., Brijs, T., \& Wets, G. (2018). Yielding behavior and traffic conflicts at cyclist crossing facilities on channelized rightturn lanes. Transportation Research Part F: Traffic Psychology and Behaviour, 55, 272-281. doi:https://doi.org/10.1016/j.trf.2018.03.012

Walker, I., \& Brosnan, M. (2007). Drivers' gaze fixations during judgements about a bicyclist's intentions. Transportation Research Part F: Traffic Psychology and Behaviour, 10(2), 90-98. doi:https://doi.org/10.1016/j.trf.2006.06.001

Werneke, J., \& Vollrath, M. (2012). What does the driver look at? The influence of intersection characteristics on attention allocation and driving behavior. Accident Analysis \& Prevention, 45(0), 610-619. doi:http://dx.doi.org/10.1016/j.aap.2011.09.048

Wickens, C. D., Goh, J., Helleberg, J., Horrey, W. J., \& Talleur, D. A. (2003). Attentional Models of Multitask Pilot Performance Using Advanced Display Technology. Human Factors, 45(3), 360-380. doi:10.1518/hfes.45.3.360.27250

Wickens, C. D., Helleberg, J., Goh, J., Xu, X., \& Horrey, W. J. (2001). Pilot task management: Testing an attentional expected value model of visual scanning. Savoy, IL, UIUC Institute of Aviation Technical Report.

Wickens, C. D., \& Horrey, W. J. (2008). Models of attention, distraction, and highway hazard avoidance. In Driver distraction: Theory, effects, and mitigation (pp. 57-69): CRC Press.

Wolfe, B., Dobres, J., Rosenholtz, R., \& Reimer, B. (2017). More than the Useful Field: Considering peripheral vision in driving. Applied Ergonomics, 65(Supplement C), 316325. doi:https://doi.org/10.1016/j.apergo.2017.07.009 